Jourhal of Emergency Primary Health Care

An International elournal of Prehospital Care Research, Education, clinical Practice, Policy and Service Delivery

ISSN 1447-4999

COCHRANE CORNER

Item No. CC990088

\title{
Biphasic versus monophasic shocks for external defibrillation in the prehospital setting
}

Paul Jennings

\section{Background}

There have been numerous studies examining the incidence of, and survival from cardiac arrest in the prehospital setting. Since the early 1960's early defibrillation has emerged as the single most important factor for improving outcomes from Ventricular Fibrillation. [1] The 1980's saw the development of the Biphasic Truncated Exponential (BTE) waveform, which was thought to be as effective or superior to standard monophasic pulses in achieving the return of an organised rhythm, whilst delivering less energy. The biphasic pulse had been effectively utilised in implantable cardioverter-defibrillators (ICDs) and it was believed that the same technology could be translated to external defibrillation. The defibrillator size and cost are directly related to the waveform shape. The biphasic (reduced energy) waveform allows for smaller, lightweight and cheaper devices to be far more widely disseminated, [2] and in turn could improve timely defibrillation.

\section{Data Source}

The Cochrane Library 2004, Issue 4

\section{Search Terms}

Prehospital Search Filter Version 1.0 [3]

Defibrillation, Cardiac Arrest, Advanced Cardiac Life Support, Sudden Death, Ventricular Fibrillation, Ventricular Tachycardia, Biphasic, Monophasic

\section{Search Results}

\section{Protocols}

None

\section{Systematic Reviews}

None

\section{Controlled Clinical Trials}

"Truncated biphasic pulses for transthoracic defibrillation". Bardy GH, Gliner BE, et al [1] "A prospective randomized evaluation of biphasic versus monophasic waveform pulses on defibrillation efficacy in humans". Bardy GH, Ivey TD, et al [4] "Multicentre comparison of truncated biphasic shocks and standard damped sine wave monophasic shocks for transthoracic ventricular defibrillation". Bardy GH, Marchlinski FE, et al [5] "A comparison of biphasic and monophasic shocks for external defibrillation". Higgins SL, Herre $\mathrm{JM}$, et al [6] 
"Optimal Response to Cardiac Arrest study: defibrillation waveform effects". Martens PR, Russell JK, et al [7]

"Transthoracic defibrillation of short-lasting ventricular fibrillation: a randomised trial for comparison of the efficacy of low-energy biphasic rectilinear and monophasic damped sine shocks". Szili-Torok T, Theuns D, et al [8]

"A prospective, randomised and blinded comparison of first shock success of monophasic and biphasic waveforms in out-of-hospital cardiac arrest". Van Alem AP, Chapman FW, et al [9]

\section{Commentary}

The search strategy identified seven clinical trials which compared low energy, biphasic external defibrillation with 200-J monophasic external defibrillation. All studies were prospective and randomised. Five of the seven trials were undertaken in a hospital environment whereby subjects were undergoing Defibrillation Threshold Testing during the insertion of an ICD. These patients were subjected to only short durations of Ventricular Fibrillation and we should remain cautious when comparing their results to those observed in the prehospital environment. Two larger trials were set in the prehospital environment [7, 9] employing emergency medical services and first responders. All seven trials concluded that low energy biphasic defibrillation were equivalent or superior to higher energy monophasic defibrillation. One study [5] reported a reduction in abnormal ST segment changes in the biphasic defibrillation group.

\section{The Bottom Line}

The evidence identified from the Cochrane library is supportive of BTE waveforms providing equivalent or superior rates of successful defibrillation to the return of an organised rhythm in cases of out-of-hospital Ventricular Fibrillation.

\section{References}

1. Bardy GH, Gliner BE, Kudenchuk PJ, Poole JE, Dolack GL, Jones GK, Anderson J, Troutman $C$, Johnson. Truncated biphasic pulses for transthoracic defibrillation. Circulation 1995;91(6):1768-74

2. Bardy GH, Marchlinski FE, Sharma AD, Worley SJ, Luceri RM, Yee R, Halperin BD, Fellows CL, Ahern TS, Chilson DA, Packer DL, Wilber DJ, Mattinoni TA, Reddy R, Kronmal RA, Lazzara R. Multicentre comparison of truncated biphasic shocks and standard damped sine wave monophasic shocks for transthoracic ventricular defibrillation. Circulation 1996;94(10):2507-2514

3. Smith E, McDonald S, Wasiak J, Jennings P, MacPherson C, Archer F. The development of a prehospital search filter for the Cochrane Library. Journal of Emergency Primary Health Care (Serial on the internet) Vol. 2, Issue 1-2, 2004, Item No. CC990071. Available from: http://www.jephc.com/full article.cfm?content id=152

4. Bardy GH, Ivey TD, Allem MD, Johnson G, Mehra R, Greene HL. A prospective randomized evaluation of biphasic versus monophasic waveform pulses on defibrillation efficacy in humans. Journal of the American College of Cardiology 1989;14(3):728-33

5. Bardy GH, Marchlinski FE, Sharma AD, Worley SJ, Luceri RM, Yee R, Halperin BD, Fellows CL, Ahern TS, Chilson DA, Packer DL, Wilber DJ, Mattinoni TA, Reddy R, Kronmal RA, Lazzara R. Multicentre comparison of truncated biphasic shocks and standard damped sine wave monophasic shocks for transthoracic ventricular defibrillation. Circulation 1996;94(10):2507-2514 
6. Higgins SL, Herre JM, Epstein AE, Greer GS, Friedman PL, Gleva ML, Porterfield JG, Chapman FW, Finkel ES, Schmitt PW, Nova RC, Greene HL. A comparison of biphasic and monophasic shocks for external defibrillation. Prehospital Emergency Care 2000;4(4):305313

7. Martens PR, Russell JK, Wolcke B, Paschen H, Kuisma M, Gilner BE, Weaver WD, Bossaert L, Chamberlain D, Schneider T. Optimal Response to Cardiac Arrest study: defibrillation waveform effects. Resuscitation 2001;49(3):233-43

8. Szili-Torok T, Theuns D, Verblaauw T, Scholten M, Kimman GJ, Res J, Jordaens L. Transthoracic defibrillation of short-lasting ventricular fibrillation: a randomised trial for comparison of the efficacy of low-energy biphasic rectilinear and monophasic damped sine shocks. Acta Cardiologica 2002;57(5):329-34

9. Van Alem AP, Chapman FW, Lank P, Hart AA, Koster RW. A prospective, randomised and blinded comparison of first shock success of monophasic and biphasic waveforms in out-ofhospital cardiac arrest. Resuscitation 2003;58(1):17-24

\section{This Article should be cited as:}

Jennings $\mathrm{P}$. Biphasic versus monophasic shocks for external defibrillation in the prehospital setting. Journal of Emergency Primary Health Care (serial on the Internet). 2004;2(3-4): Item No. CC990088. Available from: http://www.jephc.com/full_article.cfm?content_id=176 